\title{
Correlating Surface-Functionalization of Mesoporous Silica with Adsorption and Release of Pharmaceutical Guest Species
}

\author{
Victoria Morales, ${ }^{1}$ Matthew N. Idso, ${ }^{2}$ Moisés Balabasquer, ${ }^{1}$ Bradley Chmelka, ${ }^{2 *}$ Rafael \\ A. García-Muñoz ${ }^{1 *}$ \\ ${ }^{1}$ Group of Chemical and Environmental Engineering, ESCET, Rey Juan Carlos \\ University. C/ Tulipán s/n, E-28933 Móstoles, Madrid, Spain. \\ ${ }^{2}$ Department of Chemical Engineering, University of California, Santa Barbara, \\ California 93106 U.S.A.
}

\section{SUPPORTING INFORMATION}

Table S1. Quantities of amino organosilica and $\mathrm{C}_{60}$ fullerene species incorporated into mesoporous SBA-15 silica materials calculated from mass percent $\mathrm{C}$ as determined by elemental analysis, thermogravimetric analysis (TGA) and solid-state ${ }^{29} \mathrm{Si}$ single-pulse MAS NMR measurements.

\begin{tabular}{|c|c|c|c|}
\hline \multirow{2}{*}{ Sample } & \multicolumn{3}{|c|}{ mmoles of organosilica per gram of sample } \\
\hline & Calculated by $\% \mathrm{C}$ & Calculated by TGA & Calculated by ${ }^{29} \mathrm{Si}-\mathrm{NMR}$ \\
\hline SBA-15-APS & 1.63 & 1.01 & 1.10 \\
\hline SBA-15-ABS & 1.69 & 1.14 & 1.39 \\
\hline SBA-15-APhS & 1.26 & 0.97 & 0.94 \\
\hline \multirow{2}{*}{ Sample } & \multicolumn{3}{|c|}{ mmoles of $\mathrm{C}_{60}$ per gram of sample } \\
\hline & \multicolumn{2}{|c|}{ Calculated by $\% \mathrm{C}$} & Calculated by TGA \\
\hline SBA-15-APS- $\mathrm{C}_{60} \mathrm{H}$ & \multicolumn{2}{|l|}{0.17} & 0.26 \\
\hline SBA-15-ABS- $\mathrm{C}_{60} \mathrm{H}$ & \multicolumn{2}{|l|}{0.24} & 0.31 \\
\hline SBA-15-APhS-C ${ }_{60} \mathrm{H}$ & \multicolumn{2}{|l|}{0.06} & 0.01 \\
\hline
\end{tabular}


Table S2. Fitting parameters obtained by mathematical fitting of the cumulative release profiles of methylprednisolone from non-functionalized and functionalized mesoporous SBA-15 silica materials using first-order kinetic and Korsmeyer-Peppas drug release models. Beside the kinetic parameter values, the standard error is included.

\begin{tabular}{|c|c|c|c|c|c|c|c|}
\hline \multirow[b]{2}{*}{ Sample } & & \multicolumn{3}{|c|}{$\begin{array}{l}\text { First-order kinetic release model: } \\
\qquad \mathrm{F}(\mathrm{t})=\mathrm{F}_{\mathrm{o}} \cdot\left(1-\mathrm{e}^{-\mathrm{k} \cdot \mathrm{t}}\right)\end{array}$} & \multicolumn{3}{|c|}{$\begin{array}{c}\text { Korsmeyer-Peppas model: } \\
\mathrm{f}(\mathrm{t})=\mathrm{K} \cdot \mathrm{t}^{\mathrm{n}}\end{array}$} \\
\hline & & $\begin{array}{c}\text { Y-axis } \\
\text { intercept } \\
\operatorname{Ln}\left(\mathrm{F}_{\mathrm{o}}\right) \\
\end{array}$ & $\begin{array}{c}\text { Rate } \\
\text { coefficient } \\
{\left[\mathrm{min}^{-1}\right]}\end{array}$ & $R^{2}$ & $\begin{array}{l}\text { Constant, } \\
\mathrm{K}_{\mathrm{K}-\mathrm{P}}\end{array}$ & $\begin{array}{c}\text { Release } \\
\text { exponent, } \\
\mathrm{n} \\
\end{array}$ & $R^{2}$ \\
\hline SBA-15 & \multirow{5}{*}{$\begin{array}{l}\mathrm{pH} \\
7.4\end{array}$} & $0.62 \pm 0.001$ & $0.0080 \pm 0.0001$ & 0.999 & $4.3 \pm 0.9$ & $0.44 \pm 0.07$ & 0.901 \\
\hline SBA-15-APS & & $1.44 \pm 0.05$ & $0.0201 \pm 0.001$ & 0.982 & $4.2 \pm 0.5$ & $0.46 \pm 0.02$ & 0.985 \\
\hline SBA-15-ABS & & $0.26 \pm 0.004$ & $0.0034 \pm 0.001$ & 0.990 & $1.7 \pm 0.2$ & $0.54 \pm 0.02$ & 0.990 \\
\hline SBA-15-APS- $\mathrm{C}_{60} \mathrm{H}$ & & $0.55 \pm 0.02$ & $0.0072 \pm 0.0005$ & 0.970 & $4.3 \pm 0.4$ & $0.43 \pm 0.03$ & 0.985 \\
\hline SBA-15-ABS- $\mathrm{C}_{60} \mathrm{H}$ & & $0.19 \pm 0.002$ & $0.0045 \pm 0.0001$ & 0.998 & $0.6 \pm 0.1$ & $0.73 \pm 0.03$ & 0.992 \\
\hline SBA-15-APS- $\mathrm{C}_{60} \mathrm{H}$ & $\mathrm{pH}$ & $0.29 \pm 0.002$ & $0.0060 \pm 0.0001$ & 0.998 & $1.2 \pm 0.1$ & $0.53 \pm 0.02$ & 0.993 \\
\hline SBA-15-ABS-C $60 \mathrm{H}$ & 4.6 & $0.24 \pm 0.005$ & $0.0090 \pm 0.0003$ & 0.989 & $0.7 \pm 0.1$ & $0.62 \pm 0.03$ & 0.991 \\
\hline
\end{tabular}



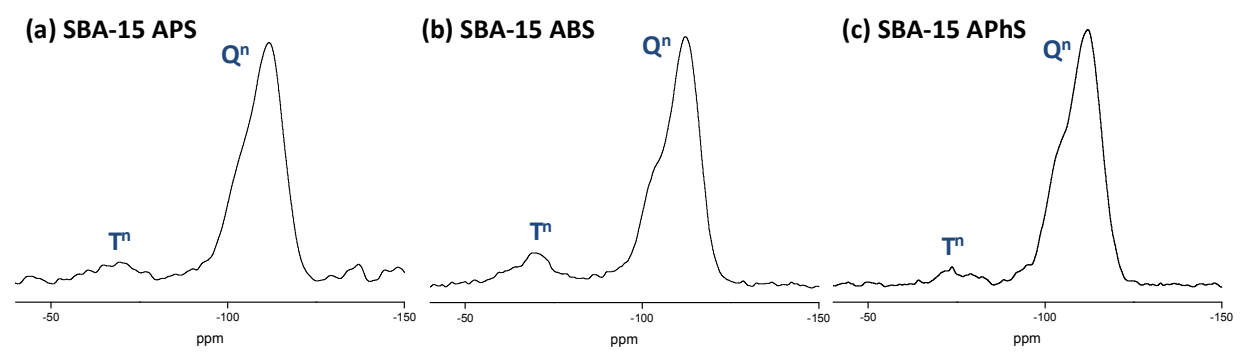

Figure S1. Solid-state 1D single-pulse ${ }^{29}$ Si MAS NMR spectra of (a) SBA-15-APS, (b) SBA15-ABS, and (c) SBA-15-APhS materials. Signals in a 1D single-pulse ${ }^{29} \mathrm{Si}$ NMR spectrum arise from chemically distinct ${ }^{29} \mathrm{Si}$ species and are resolved based on chemical shift, while their integrated areas reflect the quantities of each ${ }^{29} \mathrm{Si}$ species. Three distinct signals are observed at -110 and $-102 \mathrm{ppm}$ which are assigned to $Q^{4}$ and $Q^{329} \mathrm{Si}$ species, while the signals at ca. -65 ppm correspond to $T^{1}, T^{2}$, and $T^{3}{ }^{29} \mathrm{Si}$ associated with amino organosilica species. The quantities of amino organosilica loadings are ascertained by comparing the integrated areas of signals from $T$ and $Q$ species reveal organosilica loadings (Table S1). 
A
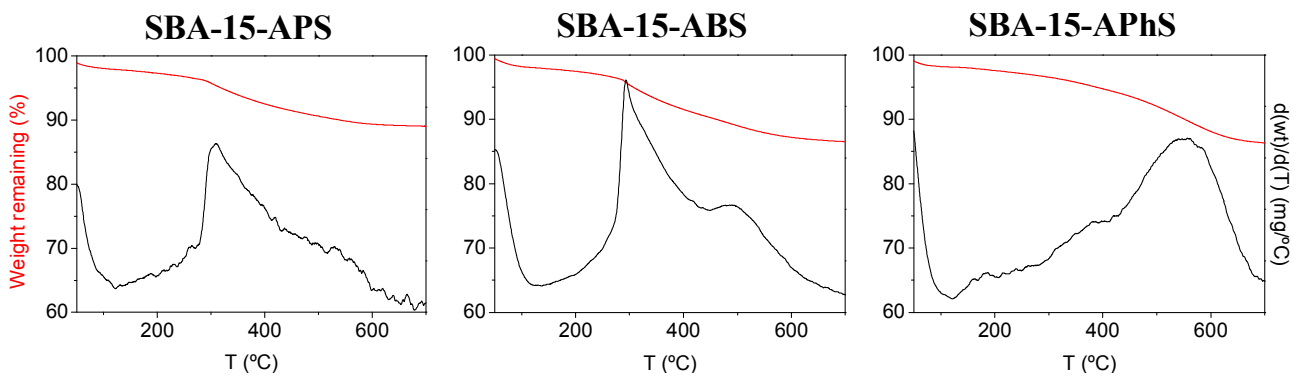

B
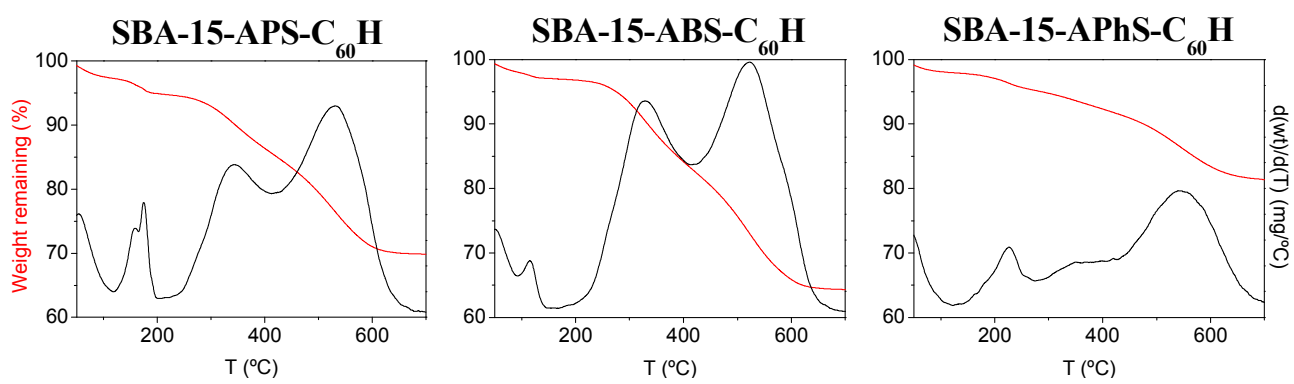

Figure S2. Thermogravimetric analyses plots of (A) SBA-15- $\mathrm{NH}_{2}$ materials (B) SBA-15-NH$\mathrm{C}_{60} \mathrm{H}$ materials. The TGA plots of SBA-15- $\mathrm{NH}_{2}$ materials (A) show mass losses between temperatures of $120{ }^{\circ} \mathrm{C}$ and $700{ }^{\circ} \mathrm{C}$ that are solely attributable to the decomposition of the organic moieties of amino organosilica species, and thus enable organosilica loadings to be quantified (Table S1). Additional mass losses are observed in the TGA plots of SBA-15-NH$\mathrm{C}_{60} \mathrm{H}$ materials (B) at temperatures of approximately $500{ }^{\circ} \mathrm{C}$, which are associated to the decomposition of fullerene $\mathrm{C}_{60}$ species. A comparison of mass losses between appropriate SBA15-NH and SBA-15-NH- ${ }_{60} \mathrm{H}$ materials allows incorporated $\mathrm{C}_{60}$ species to be quantified (Table $\mathrm{S} 1$ ). In all TGA plots, mass losses between temperatures of $40{ }^{\circ} \mathrm{C}$ and $120{ }^{\circ} \mathrm{C}$ are attributed to the removal of adsorbed water. 
(b)

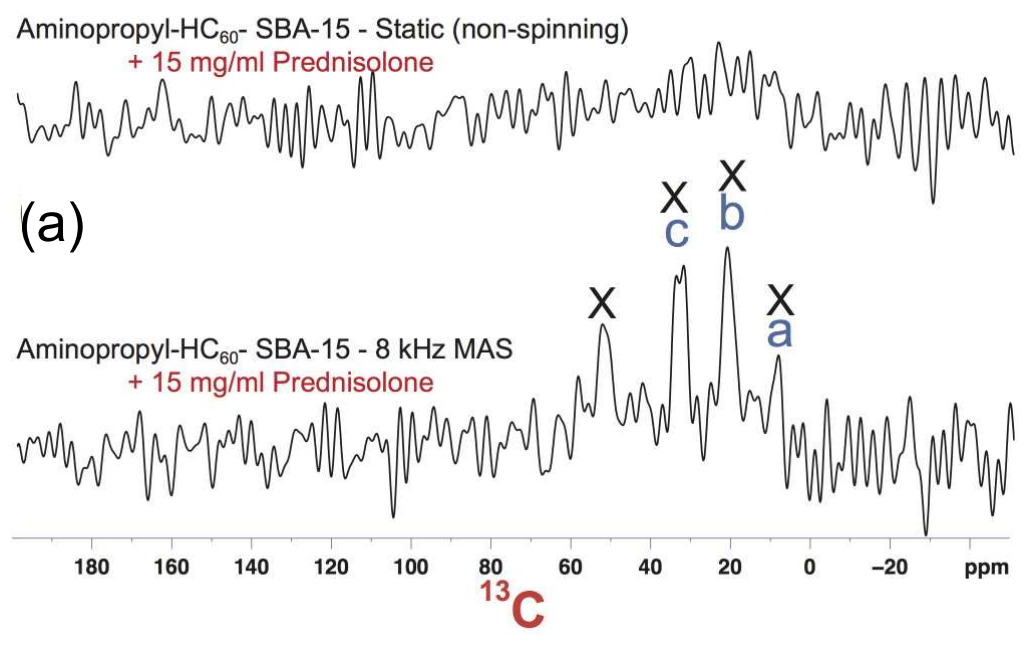

Figure S3. Solid-state $1 \mathrm{D}{ }^{13} \mathrm{C}$ CP-MAS spectra of mesoporous SBA-15 silica functionalized with $\mathrm{HC}_{60}$-aminopropyl groups with $15 \mathrm{mg} \mathrm{mL}^{-1}$ loadings of methylprednisolone guest species taken under (a) $8 \mathrm{kHz}$ MAS and (b) static (non-spinning) conditions $\mathrm{mg} \mathrm{mL}^{-1}$. The spectra were all acquired at room temperature with a $2 \mathrm{~ms} \mathrm{CP}$ contact time. 
(A) SBA-15-ABS- $\mathrm{C}_{60} \mathrm{H}$
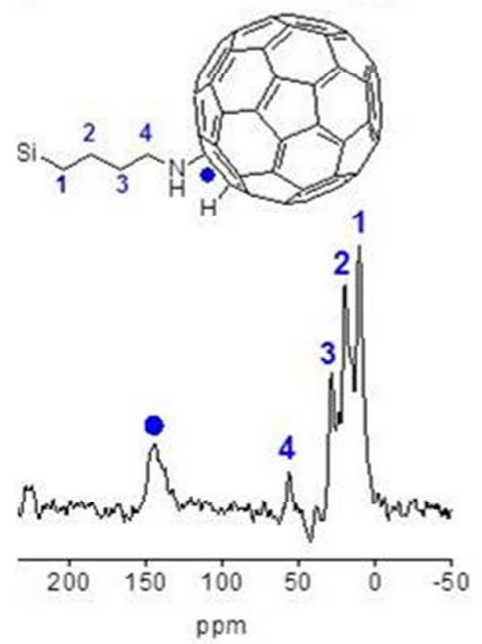

(B) SBA-15-APhS- ${ }_{60} \mathrm{H}$
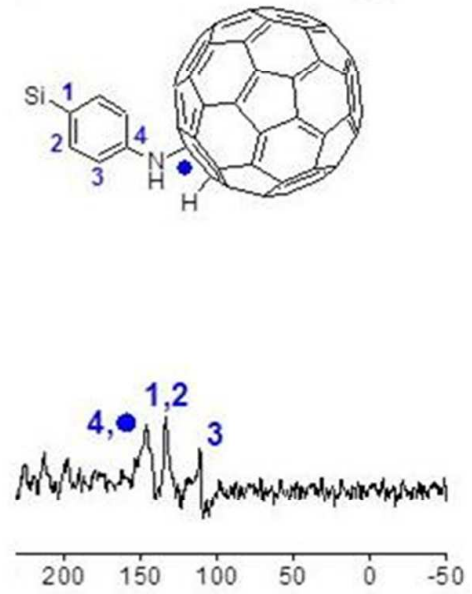

Figure S4. Solid-state $1 \mathrm{D}{ }^{13} \mathrm{C}\left\{{ }^{1} \mathrm{H}\right\}$ CP-MAS NMR spectra of (A) SBA-15-ABS- $\mathrm{C}_{60} \mathrm{H}$ and (B) SBA-15-APhS- $\mathrm{C}_{60} \mathrm{H}$ materials. In $\mathrm{A},{ }^{13} \mathrm{C}$ signals at $11,21,29$ and $57 \mathrm{ppm}$ are assignable to ${ }^{13} \mathrm{C}$ species $1,2,3$ and 4 of the aliphatic aminobutyl chains, while signals at $c a$. $145 \mathrm{ppm}$ are attributable to the aromatic ${ }^{13} \mathrm{C}$ species of the $\mathrm{C}_{60}$ fullerene moieties. In $\mathrm{B}$, the ${ }^{13} \mathrm{C}$ signals at 134 ppm are assignable to the aromatic ${ }^{13} \mathrm{C}$ groups 1 and 2, while signals at 112 and $146 \mathrm{ppm}$ are associated with ${ }^{13} \mathrm{C}$ species 3 and 4 , of the aminophenyl moieties of grafted aminophenyl organosilica species. Additionally, in $\mathrm{B}$, the ${ }^{13} \mathrm{C}$ signals at $c a .145 \mathrm{ppm}$ are associated with associated with the $\mathrm{HC}_{60}$ moieties and overlap with signals associated with species 4 of the aminophenyl moieties. Both spectra were acquired at room temperature under MAS conditions of $6 \mathrm{kHz}$ with $\mathrm{CP}$ contact times of $1 \mathrm{~ms}$. 

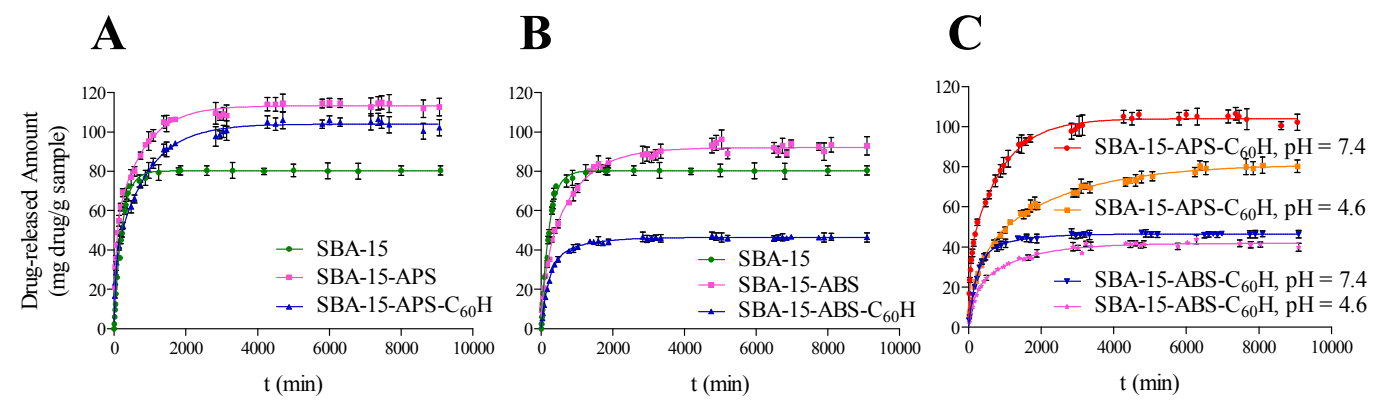

Figure S5. The cumulative profiles of methylprednisolone released into simulated body fluid $\left(\mathrm{pH}=7.4,37^{\circ} \mathrm{C}\right)$ as a percent of the methylprednisolone adsorption capacity for a given material are plotted versus time for (A) SBA-15-APS (pink, squares) and SBA-15-APS- ${ }_{60} \mathrm{H}$ (blue, triangles) materials, and (B) SBA-15-ABS (pink, squares) and SBA-15-ABS- $\mathrm{C}_{60} \mathrm{H}$ (blue, triangles). In (C), the extents of methylprednisolone released for SBA-15-APS- $\mathrm{C}_{60} \mathrm{H}$ materials into simulated body fluids at $\mathrm{pH} 7.4$ (red, circles) and $\mathrm{pH} 4.6$ (orange, squares), and from SBA15-ABS- $\mathrm{C}_{60} \mathrm{H}$ into simulated body fluids at $\mathrm{pH} 7.4$ (blue, triangles) and $\mathrm{pH} 4.6$ (pink, stars) are plotted versus time. Simulated body fluid under approximately neutral conditions ( $\mathrm{pH} 7.4$ ) was a PBS buffered solution, while simulated body fluid under acidic conditions ( $\mathrm{pH} 4.6)$ was an acetate buffered solution.

\section{References}

The complete author list of reference 34:

Uritu, C.M et al.; Varganici, C.D; Ursu, L; Coroaba, A; Nicolescu, A; Dascalu, A.I; Peptanariu, D; Stan, D; Constantinescu, C.A; Simion, V; Calin, M; Maier, S.S; Pinteala, M; Barboiu, M. 